\title{
Project-Based Learning for Electrical Engineering Lower-Level Courses
}

\section{Dr. Jiahui Song, Wentworth Institute of Technology}

Jiahui Song is an Assistant Professor in the Department of Electrical Engineering and Technology at Wentworth Institute of Technology. She received her B.S. in Automation and M.S. in Pattern Recognition \& Intelligent Systems from Southeast University. She received her Ph.D. in Electrical and Computer Engineering from Old Dominion University.

\section{Dr. Douglas E. Dow, Wentworth Institute of Technology}

Douglas Dow is an Associate Professor in the department of Electrical Engineering and Technology, starting at Wentworth Institute of Technology (Boston, MA) in 2008. He obtained a Ph.D. and M.S. in Biomedical Engineering from University of Michigan (Ann Arbor, MI), an M.S. in Computer Science from University of Colorado (Colorado Springs, CO), and a B.S. in Electrical Engineering from Texas A\&M University (College Station, TX) and a B.A. in Liberal Arts Engineering from Wheaton College (Wheaton, IL). He worked in industry for over 8 years as a new products test engineer at Ampex Corporation (the company that invented the video tape recorder) in Colorado, Panasonic's Central Research labs in Osaka, Japan, and the Institute for Systems Science at the National University of Singapore, in Singapore. He has also done biomedical research during post doctorate research positions at the University of Michigan (Ann Arbor, MI), Tohoku University (Sendai, Japan), and Mayo Clinic (Rochester, MN). He has taught classes for and been an advisor on capstone senior design projects for Wentworth students in the programs of electrical engineering, computer engineering, electromechanical engineering, and biomedical engineering. 


\title{
Project-based Learning for Electrical Engineering Lower Level Courses
}

\begin{abstract}
:
Project-based learning (PBL) is applied as an attempt to increase both understanding and sense of inspiration for a field. PBL works to integrate and apply 1) structured new knowledge covered in the course, 2) knowledge learned in other courses, 3) prior life experiential based knowledge, and 4) new self-taught knowledge. PBL and similar methods have a long tradition of being used in higher level courses, including capstone design projects. Lower level content based courses are more difficult to integrate PBL. This paper presents examples and effectiveness of this approach for electrical and computer engineering lower level courses.
\end{abstract}

Conventional courses in Logic Circuits would explain the theory and assign problem sets related to the basis for digital design with limited emphasis on applications with real world projects. In an attempt to utilize some PBL, a recent offering of this course gave the students two projects to undertake: a synchronous counter design and a 7-segnment display system. Both projects utilized Altera Quartus II software and DE2 development boards. Evaluations were based on student surveys (course evaluations) and student work (assigned homework, exams and labs). Recent offerings of this course taught in the traditional way by the same instructor resulted in only $62 \%$ of the students receiving a "B-" or higher grade for the course. In the first iteration of project-based learning, the number of students who received a "B-" or better increased to $86 \%$. Moreover, $96 \%$ of students "agree" or "strongly agree" that projects helped them to better learn the course content.

A module of Introduction to Engineering was also modified to increase PBL activity. In an attempt to add more PBL activities and make the electrical module more related to solving problems, the module was modified in scope to include both electrical and computer engineering. The students were guided through a 4 or 5 session module to generate pulse width modulation signals to control the motors of a robotic car. The additional Arduino microcontroller system offered an opportunity to increase student engagement by fun projects. After the module, $75 \%$ of students reported that they "agree" or "strongly agree" that projects helped them better to learn Electrical Engineering fundamentals. Future directions include assessing whether the students who have benefited from project-based learning will continue to be successful in their future courses.

\section{Introduction}

Project-based learning (PBL) is a dynamic method to inspire students to obtain a deeper understanding of the subjects, apply and integrate knowledge they are studying. Through PBL, students build a broader base of knowledge and skills to innovative solutions ${ }^{[1]}$. It places a lot of weight on students' involvement during their study. The approach is usually used in junior or senior design courses. Undergraduate students sometimes get a sense of boredom with theory in lower level course classrooms. PBL functions to reduce a sense of boredom and lack of purpose or relevance for students. It teaches students to explore and solve real-world problems and encourages students' desire to learn. Students who are curious and interested in the subject are better learners and more teachable. They will be more active participants in the learning process. 
Their self-directed learning skills should be enhanced, which should guide them toward becoming lifetime sustainable self-instructors.

In lower level content courses, the students need to learn specific concepts and skills in the course and they start with a smaller base of knowledge compared to when they are in upper level courses. One way to combine some of the advantages of PBL within content courses is giving the students projects, but having a structure that guides their methods to use and final specifications of the project. Within such a structure, the students have freedom to use the techniques of PBL to develop, build and test their system developed within a project. This paper presents examples and effectiveness of this approach for Electrical Engineering freshman and sophomore courses.

Logic Circuits is usually the first digital design course that is offered to the lower division undergraduate engineering students at many universities. The course provides an introduction to undergraduate students about the basis for the digital design. Besides schematic capture method for logic circuit design, the Verilog hardware description language (HDL) is another modern digital design method for programming the design and operation of digital circuits ${ }^{[2]}$. In addition, Verilog HDL designs can be downloaded on the FPGA devices, and students can check the design results on FPGA hardware ${ }^{[2]}$.

In addition, many universities have developed hands-on, team-based, first-year project courses to expose students to the application of engineering principles ${ }^{[3-8]}$. Traditionally, the labs had the students undertake exercises similar to those in a beginning circuit class, such as focusing on Ohm's Law, Kirchhoff's voltage and current laws, and voltage and current divider. With this approach, many students did not seem to become engaged. Students who were in another engineering major program or who started the module not being interested in electrical engineering did not seem to become more interested during or after the process of doing the basic circuit exercises of these labs within the module. Students did not seem to gain any insight into how these circuits could be used to solve real world applications, and their interest in the field did not increase as a whole for most of the students.

Arduino is a compact, inexpensive, open-source electronics platform built around a microcontroller ${ }^{[3]}$. It is a practical device used in engineering projects. It was found to be beneficial for several reasons ${ }^{[9]}$. The first is the device is an open-source hardware platform that is programmed using an open-source programming environment. Students can work on their own laptops ${ }^{[9]}$. Secondly, the Arduino boards are widely considered to be straight forward to use and program ${ }^{[9]}$. The Arduino hardware and software was designed for artists, designers, hobbyists ${ }^{[9]}$ The module was designed to be used for all engineering major freshmen who typically have had no or very little programming experience. Arduino environment is reported to have been used for several years in MITES (Minority Introduction to Technology, Engineering, and Science) and E2 (Engineering Experience) @ MIT, and great overviews of Arduino exist in the literature ${ }^{[10]}$. Robotics has been a popular project-based course in our Electrical Engineering program and other schools for a number of years ${ }^{[11-14]}$. While teaching the Electrical and Computer Engineering module in the new format, we introduced Arduino microcontroller within an electrical signal project, to make and test an autonomous vehicle with sensors. The project included 4 sequential labs: Lab 1 Pulse Width Modulation, Lab 2 Arduino Pulse Width 
Modulation, Lab 3 Sensors and Conditionals, and Lab 4 Autonomous Vehicle. Each lab was group work with 2 or 3 students per group.

\section{Design of Project-based Learning (PBL) Activities}

\section{Design of PBL for Logic Circuits}

Similar to the curriculum at many universities, our program has a Logic Circuits course for sophomore students in electrical engineering and computer engineering. This course is a 3 hour lecture, 2 hour lab, 4 credit course. The following topics are introduced to students: number systems, Boolean logic, Boolean algebra, K-maps, Flip-Flops, counters, and registers. Problem sets related to these topics were assigned.

To increase the amount of PBL activity, two structured projects were added to the lab section. Both projects had the students design, build and test a system using the Altera Quartus II software and DE2 board. One project was to design a Mod-6 synchronous counter . The challenge for the students was to construct a Mod-6 counter, develop the design within Quartus II, compile and simulate the design, assign pin numbers for each input and output, download the schematic circuit into the DE2 board and demonstrate the function. It was an individual project and took about one week to finish.

Another structured project was for the students to make a Verilog HDL Design for 7-segment display and test the circuit for function. This project combined the fundamentals of logic circuitsBoolean logic, Boolean algebra, and K-maps. The students were asked to determine the simplest Boolean equations for each of the display segments by using K-maps, and then to implement the 7 developed equations in Verilog HDL. Then pin numbers were added for the DE2 board. The program was downloaded, debugged and function demonstrated for the 7-segment display. This project lasted about 2 weeks and 1-2 people formed a team for the project.

\section{Design of PBL for Electrical and Computer Module of Introduction to Engineering}

Introduction to engineering is a required course for all freshmen of any engineering major at our institution. This course is a 1 hour lecture, 4 hour lab, 3 credit course. The course is designed to have 5 different lab modules: electrical, mechanical, civil, biomedical engineering, and an innovation and design thinking lab. Students are divided into 5 different groups to meet with 5 instructors from different departments. Each lab module is about 3 weeks. The main goal is to expose and potentially excite students about the various engineering fields. Introduction to Engineering has been taught in many ways. Traditionally the students would do a set of 4-6 labs in one engineering field, the next set of 4-6 labs in another engineering field, and so on. Within the electrical engineering module, the students would do a series of labs with basic circuits, such as they would do in an introductory circuit class.

Inspired by an ASEE workshop at Northeastern University that focused on interactive methods for introductory engineering courses ${ }^{[15]}$, the electrical module was modified as a series of structured PBL challenges. Part of the change was also to increase the scope of the module from only introducing electrical engineering to also introducing computer engineering. 
Lab 1 Pulse Width Modulation: the students were introduced to the basic benchtop instrumentation as used a function generator, oscilloscope and power supply. The challenge was to generate pulse-width modulation (PWM) periodic square waves to control a continuous stepper motor. This exposed the students to basic electrical engineering concepts of time-course signals, voltages, frequency and manipulations of periodic signals. Use of the bench top instruments and observation of how their different signals would control the motor allowed the students to develop some insight and confidence.

Lab 2 Arduino Pulse Width Modulation: instead of using the bench top instrument of a function generator to make the PWM signal, the students needed to write software on an Arduino microcontroller. With software and the microcontroller board, the students generated the same PWM signals that they had previously made with the function generator. This lab exposed students to the process of writing computer programs, downloading to hardware, running and testing that hardware. The trial and error experimentation and control of the motor allowed development of insight and confidence.

Lab 3 Sensors and Conditionals: sensor input to the microcontroller was introduced. Students activated sensors, setup analog-to-digital conversion on the microcontroller, and utilized the new information to generate the PWM signals controlling the motors. Using a digital multi-meter (DMM), they observed the change in voltage from the sensor as the measurand (color on the floor observed by the sensor) changed. Following analog-to-digital conversion on the microcontroller board, they observed the number from the sensor as used within the software program. Based on what they learned, they setup a threshold within the software. The concept of a conditional branch in software was introduced. The students used their found threshold to control the direction of the motors based on the color observed by the sensor. Thus the direction of the car was determined by the color of the floor observed by the sensors. The students had observation and control spanning from analog voltages from the sensor, digitized values in software, and programmed conditional branch to the behavior of motors of a car. This allowed gains in insight and confidence.

Lab 4 Autonomous Vehicle: the students utilized their prior skills to develop a target behavior for their car. The goal was to have the car generally move forward, but to stay within an arena defined by the border of a white line ring around a black floor in the interior of the ring. The cars having this behavior could then engage in a sumo like competition to see which car remains in the ring the longest.

\section{Results of Project-based Learning Activities}

\section{Course assessment of PBL for Logic Circuits:}

Table 1 provides the students' final grades when Logic Circuits were taught in the traditional way and project-based learning approach by the same instructor. There were 39 students for traditional learning and 43 students for PBL learning. 
Table 1: Students final grade distribution for Logic Circuits

\begin{tabular}{|l|c|c|c|c|c|}
\hline \multicolumn{1}{|c|}{ Final grade } & A and A- & $\begin{array}{c}\text { B+, B, and } \\
\text { B- }\end{array}$ & C+, C, and C- & D+ and D & F \\
\hline Traditional learning & $\mathbf{2 1 \%}$ & $\mathbf{4 1 \%}$ & $\mathbf{2 3 \%}$ & $\mathbf{1 0 \%}$ & $\mathbf{5 \%}$ \\
\hline $\begin{array}{l}\text { Project-based } \\
\text { learning }\end{array}$ & $\mathbf{3 3 \%}$ & $\mathbf{5 3 \%}$ & $\mathbf{9 \%}$ & $\mathbf{5 \%}$ & $\mathbf{0 \%}$ \\
\hline
\end{tabular}

When students studied the course in the traditional way, $62 \%$ of the students received A/A- and $\mathrm{B}+\mathrm{B} / \mathrm{B}-$. In the first iteration of PBL, that number of students who received $\mathrm{A} / \mathrm{A}-$ and $\mathrm{B}+\mathrm{B} / \mathrm{B}-$ jumped to $86 \%$. Also no students failed the course.

\section{Student feedback of PBL for Logic Circuits:}

A survey was conducted to collect data the last week of the semester to evaluate the contents of the projects, and students thought about project-based learning.

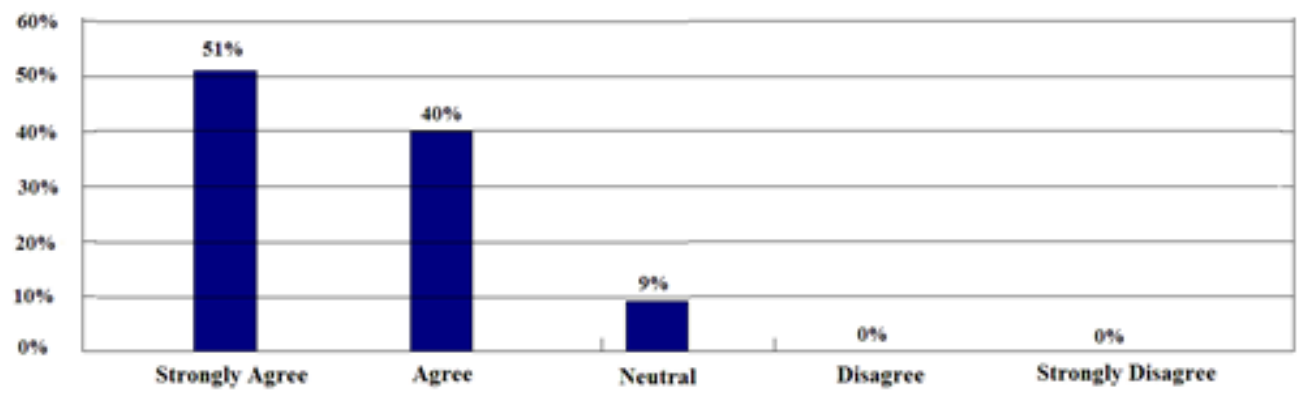

Figure 1: Results for question "The projects increased my interest in the subject."

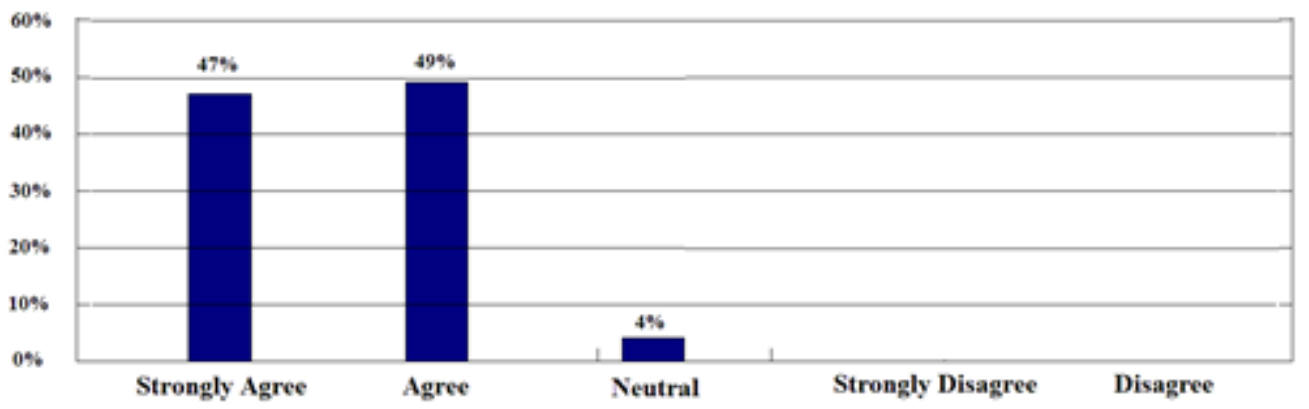

Figure 2: Results for question "The projects helped me better to learn course content."

As seen in Figure 1, 91\% of students "agree" or "strongly agree" that projects increased their interest in the subject. From Figure 2, 96\% of students "agree" or "strongly agree" that projects helped them better to learn course content. 


\section{Course assessment of PBL for Electrical and Computer module of Introduction to Engineering}

This project included both software and hardware. Students were exposed to coding (loops, conditionals, and debugging), wiring, oscilloscope, DMM, function generator, and DC power supply use. It was offered to 85 electrical engineering, computer engineering, electromechanical engineering, mechanical engineering, biomedical engineering, interdisciplinary engineering, and civil engineering freshman in Fall 2015.

Table 2 provides the students' final grades for this module. $34 \%$ of the students received A/A-, and $47 \%$ of students received $\mathrm{B}+\mathrm{B} / \mathrm{B}$-. Totally 3 groups of students showed high interest in the project. After they finished the requirements, they added more functions.

Table 2 Students final grade distribution for Electrical Engineering module

\begin{tabular}{|l|c|c|c|c|c|}
\hline \multicolumn{1}{|c|}{ Final grade } & A and A- & $\begin{array}{c}\text { B+, B, and } \\
\text { B- }\end{array}$ & C+, C, and C- & D+ and D & F \\
\hline $\begin{array}{l}\text { Percentage of } \\
\text { students }\end{array}$ & $\mathbf{3 4 \%}$ & $\mathbf{4 7 \%}$ & $\mathbf{1 2 \%}$ & $\mathbf{7 \%}$ & $\mathbf{0 \%}$ \\
\hline
\end{tabular}

\section{Student feedback of PBL for Electrical and Computer module:}

A survey was conducted to collect data the last day of Electrical Engineering module to evaluate the contents of the projects, and students thought about project-based learning.

Figure 3 presents results, wherein $72 \%$ of students "agree" or "strongly agree" that projects increased their interest in the subject. As seen from Figure 4, 75\% of students "agree" or "strongly agree" that project presented in the module increased their knowledge of the subject. As Figure 5 shows, $44 \%$ of the students think the Electrical module is excellent, $31 \%$ of the students think the module is very good and $13 \%$ of the students think the module is good.

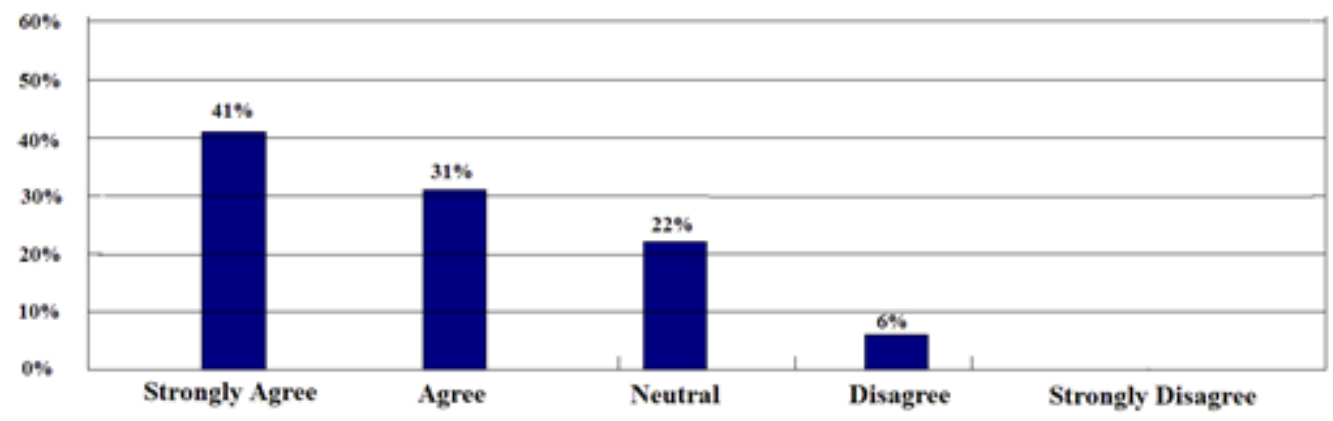

Figure 3: Results for question "The projects increased my interest in the subject." 


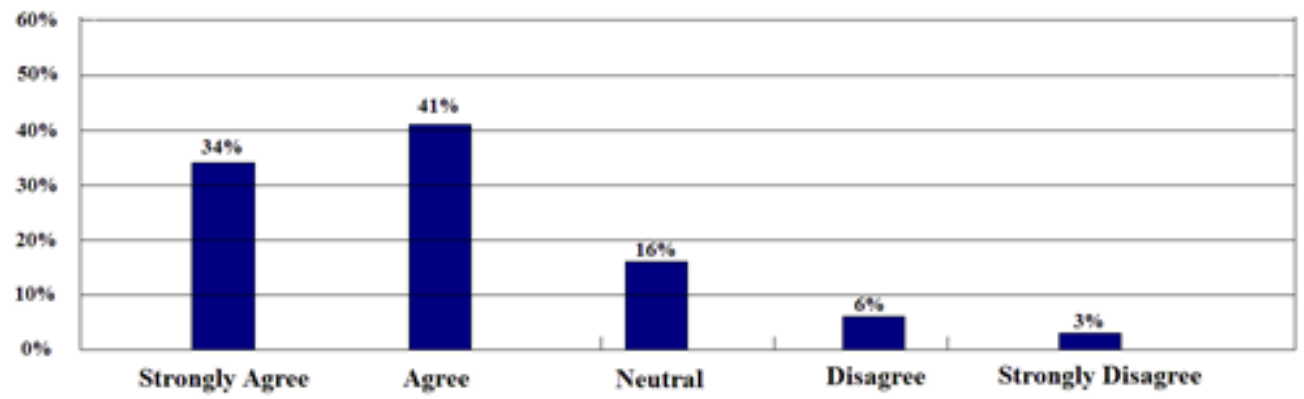

Figure 4: Results for question "The project presented in the module increased my knowledge of the subject."

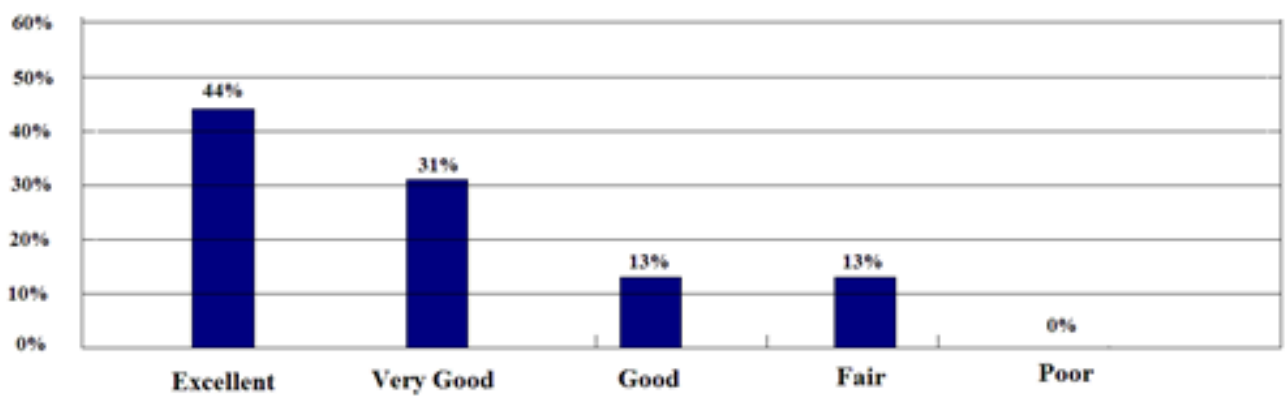

Figure 5: Results for question "What overall rating would you give the module."

Early observations show that the freshmen engineering students are applying what they learned in the Electrical and Computer Engineering Module in their later classes. After the students completed Introduction to Engineering course in the Fall term, they took Introduction to Engineering Design in the Spring term. This class has the students form teams of 2-4 students for an open design project that lasts most of the term. In prior years only a few teams would choose to do a project that involved sensors and actuators centered on a microcontroller, such as the Arduino platform. Usually those teams reported that at least one team member had used microcontrollers in the past. In contrast, this year many teams have self-selected projects based on the Arduino, and are now writing software, building circuits and testing out the systems. The majority of such teams are composed of students who had not written software, built electrical circuits and used microcontrollers prior to this Electrical and Computer Engineering module of Introduction to Engineering. But now many are using their new experience, expanded view of their own abilities, interests, and confidence to design, build and test their own microcontroller systems. We will attempt to measure this change of project scope as the design projects are completed and presented.

\section{Conclusions}

Some examples and effectiveness of structured PBL activities added to lower level courses for electrical engineering and computer engineering have been shared in this paper. PBL has a long tradition of being effective within design courses and within upper level or graduate level activities. PBL as an education method was developed most thoroughly with medical education in the 1960s has since been applied in engineering education ${ }^{[16]}$. Logic Circuits is a first 
semester sophomore course and Introduction to Engineering is a first semester freshman course. The goal of these structured PBL examples was to balance the need in content courses to have the students learn specific concepts and skills, but to also be activity engaged and explore within some of the aspects of PBL that have been found to be effective in increasing engagement. The motivation was to enhance the learning experience for the freshmen and sophomore students ${ }^{[17]}$. Based on our course assessment and student feedback, PBL encourages students to be more active participants in the learning process, and improves their performance. Also, PBL usually involves group work. Many of the engineering projects in the paper were group work. Engineers are now, more than ever, expected to collaborate and cooperate with their peers ${ }^{[17]}$. Future directions for integrating PBL in these courses include adding one more project that allows students to design from scratch in Logic Circuits, and assessing whether the students who have benefited from PBL will continue to be successful in their future courses.

\section{References:}

[1] Shekar, A. Project based Learning in Engineering Design Education: Sharing Best Practices, ASEE 120th Annual Conference and Exposition, paper ID 10806, Indianapolis, IN, 2014.

[2] Pang, J. Active Learning in the Introduction to Digital Logic Design Laboratory Course. 2015 ASEE Zone III Conference, 2015.

[3] Recktenwald, G. Using Arduino as a Platform for Programming, Design and Measurement in a Freshman Engineering Course. ASEE 118 ${ }^{\text {th }}$ Annual Conference and Exposition, Vancouver, BC, Canada, 2011.

[4] Freuler, R.J., et al. Developing and implementing hands-on laboratory exercises and design projects for first year engineering students. ASEE Annual Conference and Exposition. Albequerque, New Mexico. American Society for Engineering Education, 2001.

[5] Knight, D.W., L.E. Carlson, and J.F. Sullivan. Improving engineering student retention through hands-on, team based, first-year design projects. 1st International Conference on Research in Engineering Education. Honolulu, Hawaii. June 22-24, 2007. American Society for Engineering Education.

[6] Knight, D.W., L.E. Carlson, and J.F. Sullivan. Staying in engineering: impact of a hands-on, team-based, firstyear projects course on student retention. ASEE Annual Conference and Exposition. Nashville, Tennessee. American Society for Engineering Education, 2003.

[7] Hall, D., H. Hegab, and J. Nelson. Living WITH the Lab - A Freshman Curriculum to Boost Hands-on Learning, Student Confidence and Innovation. ASEE/IEEE Frontiers in Education Conference. Saratoga Springs, NY. October 22-25, 2008.

[8] Mara, R.M., B. Palmer, and T.A. Litzinger, The effects of a first-year engineering design course on student intellectual development as measured by the Perry scheme. Journal of Engineering Education, p. 39-45, 2000.

[9] Bird, N. Use of the Arduino Platform for a Junior-Level Undergraduate Microprocessors Course.

American Society of Engineering Education Annual Conference, 2011.

[10] Steinmeyer, J. Project-based Learning with Single-Board Computers, ASEE 122th Annual Conference and Exposition, paper ID 13644, Seattle, WA, 2015.

[11] Walter, W. W. \& Southerton, T. G. Teaching Robotics by Building Autonomous Mobile Robots Using the Arduino. American Society of Engineering Education Annual Conference, 2014.

[12] Lau, K. W., Erwin, B. T. \& Petrovic, P. Creative learning in school with LEGO(R) programmable robotics products. FIE'99 Frontiers in Education. 29th Annual Frontiers in Education

Conference. Designing the Future of Science and Engineering Education. Conference Proceedings

(IEEE Cat. No.99CH37011 2, 12D4/26-12D4/31 (Stripes Publishing L.L.C, 1999).

[13] Erwin, B., Cyr, M. \& Rogers, C. LEGO Engineer and RoboLab: Teaching Engineering with LabVIEW from Kindergarten to Graduate School. at

<http://www.researchgate.net/publication/246676439_LEGO_Engineer_and_RoboLab_Teaching_ Engineering_with_LabVIEW_from_Kindergarten_to_Graduate_School> 
[14] Williams, A. B. The qualitative impact of using LEGO MINDSTORMS robots to teach computer engineering. IEEE Trans. Educ. 46, 206-206, 2003.

[15] Grahame, K. S., Freeman, S., Goldthwaite, D., Love, J., Pfluger, C., Maheswaran, B., Hertz, J., Variawa, C., "Shall I Try This? An interactive workshop on assessing hands-on teaching", American Society for Engineering Education (ASEE) Northeast Section Conference, Boston, MA, April 30, 2015.

[16] Hitt, J. Problem-Based Learning in Engineering. United States Military Academy, West Point, NY, 2010.

[17] Bédard, D. , Lison, C. , Dalle, D. , Côté, D. , \& Boutin, N. Problem-based and Project-based Learning in Engineering and Medicine: Determinants of Students' Engagement and Persistance. Interdisciplinary Journal of Problem-Based Learning, 6(2), 2012. 